\begin{tabular}{|c|c|}
\hline Journal STAND: Sports and Development & http://jurnal.unipasby.ac.id/index.php/stand/about/submissions \\
unipa Sumalaya & jurnal.stand@unipasby.ac.id
\end{tabular}

\title{
PENGEMBANGAN MODEL PEMBELAJARAN KERJASAMA TIM DALAM EFEKTIVITAS PENGUASAAN GERAKAN SENAM DASAR PRESTASI
}

\author{
Abd. Cholid ${ }^{1}$, Harwanto ${ }^{2}$ \\ Program Magister Pendidikan Jasmani, Pascasarjana Universitas PGRI Adi Buana Surabaya \\ abdcholid@unipasby.ac.id ${ }^{1}$, harwanto@unipasby.ac.id ${ }^{2}$
}

\begin{tabular}{l}
\hline Artikel Info \\
\hline Koresponden penulis : \\
Abd. Cholid \\
Email: \\
abdcholid@unipasby.ac.id \\
Diterima 27 April 2020 \\
Direview 12 Mei 2020 \\
Disetujui 12 Mei 2020 \\
Dipublikasi 27 Mei 2020 \\
\\
\\
Kata Kunci: \\
Pengembangan Kembelajaran, Kerjasama tim, \\
gengektifitas penguasan gerakan \\
senam dasarprestasi \\
\hline
\end{tabular}

Keywords:

Development of Learning Models,

Teamwork, effectiveness of mastery

of the basic gymnastics achievement

achievements

\begin{abstract}
Abstrak
Pengembangan model pembelajaran kerjasama tim diterapkan dalam proses belajar dan mengajar (PBM) sebagai upaya untuk meningkatkan efektivitas penguasaan gerakan senam dasar prestasi, yang merupakan salah satu alternatif model pembelajaran yang efektif untuk mencapai hasil belajar latihan gerak senam dasar prestasi secara praktis. Hal tersebut didasarkan pada pemikiran bahwa berlatih kerjasama tim dapat memberikan kontribusi yang positif dalam pengembangan diri maupun kepraktisan dalam berlatih praktek, karena kerjasama tim mampu membangun kompetensi dan karakter siswa melalui penanaman nilai sikap kerjasama, disiplin, saling hormat dan menghargai teman dalam tim, serta membangun rasa percaya diri.

Penelitian ini dilakukan untuk mengembangkan Model Pembelajaran melalui kerjasama tim dalam berlatih gerak senam dasar prestasi dan melihat tingkat keefektifan dalam Pengusaan Gerakan Senam dasar prestasi. Diharapkan hasil penelitian ini dapat memberikan kontribusi yang positif pada dosen dan guru pengampu materi senam dasar prestasi melalui pengembangan model latihan kerjasama tim yang efektif dalam penguasaan gerakan senam dasar prestasi.

Berdasarkan hasil penelitian, maka dapat disimpulkan sebagai berikut; 1). Model pembelajaran latihan Kerjasama tim dapat meningkatkan efektivitas dalam penguasaan gerakan senam dasar prestasi2). Penerapan model pembelajaran latihan Kerjasama tim dapat dijadikan sebagai salah satu alternatif dalam menentukan model pembelajaran.
\end{abstract}

\begin{abstract}
The development of the teamwork learning model is applied in the learning and teaching process (PBM) as an effort to improve the effectiveness of mastery of basic gymnastics achievement achievements, which is one alternative effective learning model to achieve learning outcomes of practical exercise exercises based on practical achievement. This is based on the idea that practicing teamwork can make a positive contribution in selfdevelopment and practicality in practicing practice, because teamwork is able to build student competencies and characters through instilling the values of cooperation, discipline, mutual respect and respect for friends in the team, as well as building confident. This research was conducted to develop a Learning Model through teamwork in practicing the basic gymnastic movements of achievement and see the level of effectiveness in the Mastering of the Basic Gymnastics Movement for achievement. It is expected that the results of this study can make a positive contribution to the lecturers and teachers who support the basic gymnastics achievement material through the development of an effective teamwork training model in mastering the basic gymnastics achievement movement.

Based on the results of the study, it can be concluded as follows; 1). The learning model of training Teamwork can increase effectiveness in mastering the basic gymnastic movements achievement2). Application of the learning model of training Teamwork can be used as an alternative in determining learning models.
\end{abstract}




\begin{tabular}{|c|c|}
\hline & Journal STAND: Sports and Development \\
\hline umipa Sumalaya & http://jurnal.unipasby.ac.id/index.php/stand/about/submissions \\
\hline
\end{tabular}

\section{PENDAHULUAN}

\section{A. Model Pembelajaran}

Proses pembelajaran akan berhasil jika ditentukan oleh beberapa faktor yang memengaruhinya, baik secara internal maupun eksternal. Namun ketika siswa dihadapkan pada persoalan pengusaan materi secara praktis tentu hal ini perlu metode secara khusus. Inilah yang menjadi pemikiran kami untuk mendapatkan solusi hasil yang maksimal khususnya pada penguasan skills atau keterampilan anak dalam melakukan gerak senam dan rangkaian senam dasar prestasi, tentu butuh strategi khusus dalam menerapkan model pembelajarannya. Pembelajaran yang dimaksud seharusnya berupa kegiatan yang dilakukan untuk menciptakan suasana atau memberikan pelayanan agar siswa belajar dengan nyaman, senang dan imaginative serta dikemas secara koordinatif. Untuk itu, seorang Pendidik harus memahami bagaimana cara siswa memeroleh pengetahuan dari kegiatan belajarnya dengan efektif dan efisien. Harapannya guru dapat memahami bagaimana proses cara pemerolehan pengetahuan, dan keterampilan motorik maka guru akan dapat menentukan strategi pembelajaran yang tepat bagi siswanya. Sebagaimana Nasution (2005) mendefinisikan Model pembelajaran sebagai suatu aktifitas mengorganisasi atau mengatur lingkungan sebaik-baiknya dan menghubungkannya dengan anak didik sehingga terjadi proses belajar. Lingkungan dalam pengertian ini tidak hanya ruang belajar, tetapi juga meliputi guru, alat peraga, perpustakaan, laboratorium, dan sebagainya yang relevan dengan kegiatan belajar siswa.

Dengan demikian dapat dikatakan bahwa Model Pembelajaran adalah suatu perencanaan atau suatu pola yang digunakan sebagai pedoman dalam merencanakan pembelajaran di kelas. Model pembelajaran mengacu pada pendekatan pembelajaran yng akan digunakan, termasuk didalamnya tujuan pengajaran, tahapan dalam kegiatan pembelajaran, lingkungan pembelajaran dan pengelolaan kelas.

Sedangkan Fungsi model pembelajaran adalah sebagai pedoman bagi perancang pengajar dan para guru dalam melaksanakan pembelajaran.

Model pembelajaran memunyai 4 ciri khusus yang tidak dimiliki oleh strategi, metode, atau prosedur, ciri-ciri khusus model pembelajaran yakni meliputi:

1. Rasional teoritis logis yang disusun oleh para pencipta atau pengembangnya. Model pembelajaran memunyai teori berpikir yang masuk akal

2. Landasan pemikiran tentang apa dan bagaimana siswa belajar (tujuan pembelajaran yang akan dicapai). Model pembelajaran memunyai tujuan yang jelas tentang apa yang akan dicapai, termasuk didalamnya apa dan bagaimana siswa belajar dengan baik serta 


\begin{tabular}{|c|c|c|}
\hline Journal STAND: Sports and Development \\
\hline unipa Sumabaya & $\mathrm{http} / /$ jurnal.unipasby.ac.id/index.php/stand/about/submissions \\
\hline
\end{tabular}

cara memecahkan suatu masalah pembelajaran.

3. Tingkah laku mengajar yang diperlukan agar model tersebut dapat dilaksanakan dengan berhasil. Model pembelajaran memunyai tingkah laku mengajar yang diperlukan, sehingga apa yang menjadi citacita mengajar selama ini dapat berhasil dalam pelaksanaannya.

4. Lingkungan belajar yang diperlukan agar tujuan pembelajaran itu dapat tercapai. Model pembelajaran memunyai lingkungan belajar yang kondusif serta nyaman, sehingga suasana belajar dapat menjadi salah satu aspek penunjang apa yang selama ini menjadi tujuan pembelajaran.

Selanjutnya setiap model pembelajaran memerlukan system pengelolaan dan lingkungan belajar yang berbeda. Setiap pendekatan memberikan peran yang berbeda kepada siswa, pada ruang fisik, dan pada system social kelas.

Tujuan yang dicapai meliputi aspek kognitif, afektif dan psikomotor

\section{B. Senam Dasar Prestasi}

Senam Dasar Prestasi merupakan gerakan senam dan rangkaian gerakan yang banyak melibatkan unsur kekuatan, kelentukan, keseimbangan dan unsur koordinasi. Senam Dasar Prestasi secara umum merupakan satu gerakan tubuh yang banyak melibatkan banyak unsur motorik dan sistem otot.

Pengertian senam dasar prestasi tersebut mengandung makna dua unsur yang saling menghubungkan gerakan dan pikiran. Dengan demikian senam dasar prestasi merupakan salah satu cabang olahraga sekali sebagai materi mata kuliah wajib harus tempuh bagi mahasiswa yang sarat praktek gerakannya melibatkan banyak unsur motorik dan melibatkan system kerja otot secara maksimal.

Dalam kaitannya dengan penelitian ini, kami ingin mengembangkan pola pembelajaran yang efektif melalui model pembelajaran kerjasama tim dengan harapan dapat memudahkan dalam penguasaan gerakan baik pada latihan senam maupun latihan rangkaian gerakan senam.

\section{Peran Kerjasama tim}

Kerjasama tim bisa diartikan kerja tim atau kerjasama, kerjasama tim atau kerja sama tim merupakan bentuk kerja kelompok dengan keterampilan yang saling melengkapi serta berkomitmen untuk mencapai target yang sudah disepakati sebelumnya untuk mencapai tujuan bersama secara efektif dan efisien. Harus disadari bahwa kerjasama tim merupakan peleburan berbagai pribadi yang menjadi satu pribadi untuk mencapai tujuan bersama. Tujuan tersebut bukanlah tujuan pribadi, bukan tujuan ketua tim, bukan pula tujuan dari pribadi yang paling populer di tim.

Dalam sebuah tim yang dibutuhkan adalah kemauan untuk saling bergandengtangan menyelesaikan pekerjaan. Bisa jadi satu orang tidak menyelesaikan pekerjaan atau tidak ahli dalam pekerjaan $\mathrm{A}$, namun dapat dikerjakan oleh anggota tim lainnya. 


\begin{tabular}{|c|c|}
\hline Journal STAND: Sports and Development & http://jurnal.unipasby.ac.id/index.php/stand/about/submissions \\
\hline unipa Sunalaya & jurnal.stand@unipasby.ac.id
\end{tabular}

Inilah yang dimaksudkan dengan kerja tim, beban dibagi untuk satu tujuan bersama.

Saling mengerti dan mendukung satu sama lain merupakan kunci kesuksesan dari kerjasama tim. Jangan pernah mengabaikan pengertian dan dukungan ini. Meskipun terjadi perselisihan antar pribadi, namun dalam tim harus segera menyingkirkannya terlebih dahulu. Bila tidak kehidupan dalam tim jelas akan terganggu, bahkan dalam satu tim bisa jadi berasal dari latar belakang divisi yang berbeda yang terkadang menyimpan pula perselisihan. Oleh karena itu, penting untuk menyadari bahwa kebersamaan sebagai anggota tim di atas segalanya.

Keakraban tim yang sukses biasanya ditandai dengan sikap akrab satu sama lain, setia kawan, dan merasa senasib sepenanggungan. Para anggota tim saling menyukai dan berusaha keras untuk mengembangankan dan memelihara hubungan interpersonal. Hubungan interpersonal menjadi sangat penting karena hal ini akan merupakan dasar terciptanya keterbukaan dan komunikasi langsung serta dukungan antara sesama anggota team.

Kerjasama tim merupakan sarana yang sangat baik dalam menggabungkan berbagai talenta dan dapat memberikan solusi inovatif suatu pendekatan yang mapan, selain itu ketrampilan dan pengetahuan yang beranekaragam yang dimiliki oleh anggota kelompok juga merupakan nilai tambah yang membuat kerjasama tim lebih menguntungkan jika dibandingkan seorang individu yang brilian sekalipun.

Kerjasama tim dapat didefinisikan sebagai kumpulan individu yang bekerjasama untuk mencapai suatu tujuan. (Alexandria: ASCD. Maggi, S. \& Claire H.M. (2004). Kumpulan individu-individu tersebut memiliki aturan dan mekanisme kerja yang jelas serta saling tergantung antara satu dengan yang lain. Oleh karena itu sekumpulan orang yang bekerja dalam satu ruangan, bahkan didalam satu proyek, belum tentu merupakan sebuah kerjasama tim. Terlebih lagi jika kelompok tersebut dikelola secara otoriter, timbul faksi-faksi di dalamnya, dan minimnya interaksi antar anggota kelompok. Beberapa isu di dalam tim menurut Richard. I. (2008):

1. Adanya tugas (task) dan masalahmasalah yang berhubungan dengan pelaksanaan pekerjaan. Hal ini seringkali merupakan topik utama yang menjadi perhatian team.

2. Proses yang terjadi di dalam kerjasama tim itu sendiri, misalnya bagaimana mekanisme kerja atau aturan main sebuah team sebagai suatu unit kerja dari perusahaan, proses interaksi di dalam tim, dan lain-lain

Keuntungan pengambilan keputusan dalam tim menurut Barbara. B. Levin., dalam Rachmad. (2001) :

1. Keputusan yang dibuat secara bersamasama akan meningkatkan motivasi team dalam pelaksanaanya. 


\begin{tabular}{|c|c|}
\hline Journal STAND: Sports and Development \\
unipa Sumalaya & http://jurnal.unipasby.ac.id/index.php/stand/about/submissions \\
jurnal.stand@unipasby.ac.id
\end{tabular}

2. Keputusan bersama akan lebih mudah dipahami oleh team dibandingkan jika hanya mengandalkan keputusan dari satu orang saja

\section{Manfaat dan Fungsi Kerjasama tim}

Bekerja dalam bentuk tim memiliki fungsi yaitu antara lain dapat merubah sikap, perilaku dan nilai-nilai pribadi serta dapat turut serta dalam mendisiplinkan anggota tim, (Amir, M. Taufiq. (2009). Selain itu, bekerja dalam tim dapat dimanfaatkan untuk pengambilan keputusan, merundingkan dan bernegoisasi.

1. Manfaat Bekerja Dalam Tim

a) Bagi Organisasi Tim

(1) Meningkatkan produktivitas kerja.

(2) Meningkatkan kualitas kerja.

(3) Meningkatkan mentalitas kerja.

(4) Meningkatkan kemajuan organisasi.

b) Bagi Anggota Tim

(1) Tanggung jawab atas pekerjaan ditanggung bersama.

(2) Sebagai media aktualisasi diri.

(3) Stres atau beban kerja berkurang.

2. Tujuan Bekerja Dalam Tim

a) Kesatuan Tujuan

Setiap anggota tim memiliki kesamaan visi,misi dan program kerja.

b) Efisiensi

Setiap anggota tim menyelesaikan tugas atau pekerjaan secara cepat,cermat dan tepat tanpa pemborosan dan kecerobohan.

c) Efektif

Setiap anggota tim memiliki tujuan yang jelas, memiliki keterampilan yang memadai, memiliki komitmen, saling percaya, memiliki komunikasi yang baik, memiliki kemampuan bernegoisasi, dan memiliki kemampuan yang tepat.

\section{E. JENIS KERJASAMA TIM}

Menurut Daft (2000) jenis kerjasama tim terdiri dari enam jenis, yaitu:

\section{Tim Formal}

Tim formal adalah sebuah tim yang dibentuk oleh organisasi sebagai bagian dari struktur organisasi formal.

\section{Tim Vertikal}

Tim vertikal adalah sebuah tim formal yang terdiri dari seorang manajer dan beberapa orang bawahannya dalam rantai komando organisasi formal.

3. Tim Horizontal

Tim horizontal adalah sebuah tim formal yang terdiri dari beberapa karyawan dari tingkat hirarki yang hampir sama tetapi berasal dari area keahlian yang berbeda.

4. Tim dengan Tugas Khusus

Tim dengan tugas khusus adalah sebuah tim yang dibentuk di luar organisasi formal untuk menangani sebuah proyek dengan kepentingan atau kreativitas khusus.

\section{Tim Mandiri}

Tim Mandiri adalah sebuah tim yang terdiri dari lima hingga dua puluh orang pekerja dengan beragam keterampilan yang menjalani rotasi pekerjaan untuk menghasilkan sebuah produk atau jasa secara lengkap, dan pelaksanaannya diawasi oleh seorang annggota terpilih.

6. Tim Pemecahan Masalah 


\begin{tabular}{|c|c|}
\hline Journal STAND: Sports and Development & http://jurnal.unipasby.ac.id/index.php/stand/about/submissions \\
\hline unipa Sunalaya & jurnal.stand@unipasby.ac.id
\end{tabular}

Tim pemecahan masalah biasanya terdiri dari lima hingga dua belas karyawan yang dibayar perjam dari departemen yang sama, dimana mereka bertemu untuk mendiskusikan cara memperbaiki kualitas, efisiensi, dan lingkungan kerja.

\section{F. MODEL EFEKTIFITAS KERJASAMA TIM}

Efektifitas tim kerja didasarkan pada dua hasil - hasil produktif dan kepuasan pribadi. Kepuasan berkenaan dengan kemampuan tim

\begin{tabular}{|c|c|c|c|}
\hline Kelompok & $\begin{array}{c}\text { Pre } \\
\text { test }\end{array}$ & $\begin{array}{c}\text { Treat } \\
\text { ment }\end{array}$ & $\begin{array}{c}\text { Post } \\
\text { test }\end{array}$ \\
\hline $\mathrm{E}_{1}$ & $\mathrm{~T}_{1}$ & $\mathrm{X}_{1}$ & $\mathrm{~T} 2_{1}$ \\
\hline
\end{tabular}

untuk memenuhi kebutuhan pribadi para anggotanya dan kemudian mempertahankan keanggotaan serta komitmen mereka. Hasil produktif berkenaan dengan kualitas dan kuantitas hasil kerja seperti yang didefinisikan oleh tujuan - tujuan tim. Faktor - faktor yang mempengaruhi efektifitas tim yaitu konteks organisasional, struktur, strategi, lingkungan budaya, dan system penghargaan. Karakter tim yang penting adalah jenis, struktur, dan komposisi tim. Karakteristik - karakteristik tim ini mempengaruhi proses internal tim, yang kemudian mempengaruhi hasil dan kepuasan, (Rusman. (2012). Para pemimpin harus memahami dan mengatur tingkat - tingkat perkembangan, kekompakan, norma - norma, dan konflik supaya dapat membangun tim yang efektif.

\section{G. METODE PENELITIAN}

Penelitian ini termasuk jenis penelitian Pengembangan yakni mengembangkan efektifitas metode pembelajaran yang difokuskan pada latihan praktek melalui pembelajaran Tim work, dimana nantinya dapat menghasilkan karya buku ajar. Untuk rancangan model yang dibangun yakni dengan penerapan model kerjasama tim dengan beberapa stimulan latihan gerakan senam dan rankaian gerakan. Selanjutnya subyek penelitian akan dilakukan uji pre test dan Post Test selama waktu penelitian. Adapun rancangan penelitian ini dapat digambarkan sebagai berikut:

Keterangan:

$\mathrm{T} 1$ :Pretest subyek penelitian

$\mathrm{X}_{1}$ :Treatment

T2 :Post test subyek penelitian

\section{Populasi dan Sampel Penelitian}

a. Populasi

Populasi penelitian ini adalah Mahasiswa S1 Pendidikan Jasmani Angkatan 2018 Universitas Adi Buana yang sedang memrogram mata kuliah senam dasar prestasi semester Genap 2018/2019

\section{b. Sampel}

Sampel merupakan bagian dari jumlah dan karateristik yang dimiliki oleh populasi tersebut (Sugiono, (2010: 116). Selanjutnya yang dijadikan sampel dalam penelitian ini sebanyak 30 orang dari sejumlah populasi dengan menggunakan teknik simple random sampling (pengundian). 


\begin{tabular}{|c|c|}
\hline Journal STAND: Sports and Development & http://jurnal.unipasby.ac.id/index.php/stand/about/submissions \\
\hline unipa Sunalaya & jurnal.stand@unipasby.ac.id
\end{tabular}

Kemudian dilakukan pretest terhadap orang coba sejumlah 30 mahasiswa, ini dimaksudkan untuk mengetahui kemampuan awal dari pada sampel.

\section{c. Instrumen Penelitian}

Instrumen yang digunakan untuk mengukur kemampuan dasar adalah dengan cara memberikan materi gerakan senam dasar prestasi yang selanjutnya subyek mendapat treatment materi tersebut dengan model Kerjasama tim selama waktu yang ditentukan (3 bln).

\section{d. Teknik Analisis Data}

Sesuai dengan jenis penelitian ini, maka analisis statistic yang digunakan adalah

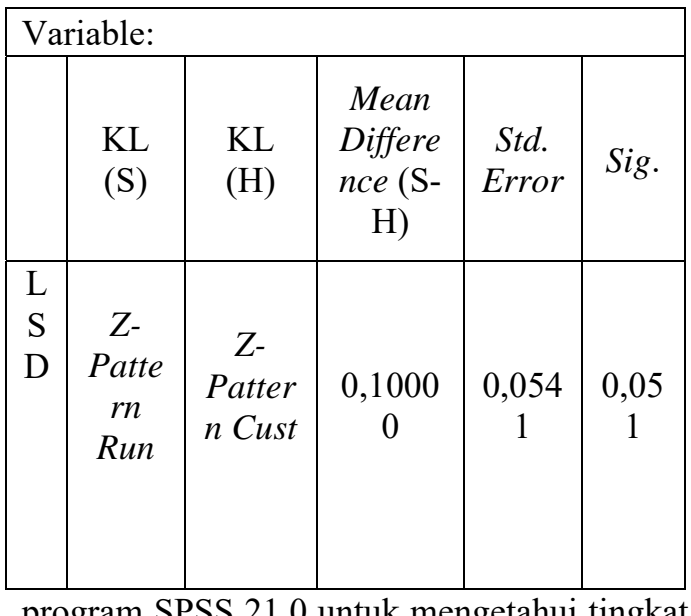

efektifitas metode pembelajarannya dianalisis melalui rumus prosentase.

\section{H. HASIL PENELITIAN}

\section{Analisis Data}

Berdasarkan hasil analisis data menunjukkan bahwa terdapat sebuah peningkatan yang signifikan nilai rerata antara pretest dan posstest. Hal ini dapat dilihat dari nilai rerata untuk test gerakan senam dan gerakan rangkaian pada pretest sebesar 62,47) sedangkan pada hasil posttest $(77,26)$, ini menunjukan bahwa dalam penerapan metode pembelajaran latihan Kerjasama tim melalui treatment selama kurun waktu tertentu dapat memberikan kontribusi yang positif dan signifikan, hal ini juga dibuktikan dengan peningkatan nilai prosentase sebesar $22.74 \%$ Dengan demikian metode pembelajaran latihan Kerjasama tim dapat dijadikan sebagai alternative model pembelajaran yang efektif dalam penerapan latihan praktek khususnya gerakan senam dasar prestasi.

Selisih rerata tersebut menunjukkan adanya peningkatan setelah diberikan perlakuan selama dua belas minggu dengan frekuensi dua kali seminggu.

Berdasarkan hasil analisis diatas pada perhitungan rerata sampel dengan penerapan model kerjasama tims dengan menggunakan uji-t hasilnya ada peningkatan efektivitas waktu dan penguasaan gerakan senam dasar prestasi pada mahasiswa S1 Pendidikan Jasmani Unipa Surabaya.

\section{PEMBAHASAN}

Dari hasil analisis data menunjukan adanya perbedaan angka penghitungan secara signifikan terkait peningkatan kompetensi mahasiswa dalam memahami dan mempraktekan gerakan senam dasar prestasi secara sistematis. Hal ini menunjukkan bahwa pelatihan pembelajaran dengan model Kerjasama tim dapat memengaruhi kinerja gerak mahasiswa baik secara efektivitas 


\begin{tabular}{|c|c|}
\hline Journal STAND: Sports and Development & http://jurnal.unipasby.ac.id/index.php/stand/about/submissions \\
\hline unipa Sumalaya & jurnal.stand@unipasby.ac.id
\end{tabular}

waktu maupun penguasaan gerakan menerapkan model pembelajaran kerjasama khususnya pada senam dasar prestasi. Oleh tim, karena metode ini sudah teruji melalui karenanya keberhasilan dalam proses research.

pembelajaran itu menurut pemikiran peneliti terletak pada bagaimana memilih model pembelajaran yang sesuai dengan karakter mahasiswa. Satu kelebihan dalam penerapan model pembelajaran kerjasama tim adalah:

1) membangun sikap kebersamaan dan saling menghormati dalam tim

2) saling memberi dan menerima masukan (take and gives)

3) Hemat waktu untuk menguasai sebuah tugas gerakan

4) membangun mindset cara berpikir yang logis dan praktis

\section{J. SIMPULAN}

Berdasarkan hasil penelitian diatas, maka dapat disimpulkan sebagai berikut:

1. Model pembelajaran latihan Kerjasama tim dapat meningkatkan efektivitas dalam penguasaan gerakan senam dasar prestasi

2. Penerapan model pembelajaran latihan Kerjasama tim dapat dijadikan sebagai salah satu alternatif dalam menentukan model pembelajaran

\section{K. SARAN}

Berdasarkan hasil penelitian ini dapat disarankan bahwa untuk memilih sebuah model pembelajaran yang tepat sesuai dengan karakter kelas yang efektif adalah dengan

\section{DAFTAR PUSTAKA}

Alexandria: ASCD. Maggi, S. \& Claire H.M. (2004). Foundations of problem-based learning. New York: Open University Press.

Barbara. B. Levin. dalam Rachmad (2001): Energizing teacher education and profesional development with problem based learning.

Daft; Johnson \& Johnson. (2000). Cooperative Learning Strategis (online): www.clcrc.com/cl.html

Richard. I. (2008). Belajar untuk mengajar. Edisi ke tujuh alih bahasa oleh Helly Prayitno dan Sri Mulyantani Prayitnodari judul Learning to Teach (7thed). Yogyakarta: Penerbit Pustaka Pelajar.

Rusman. (2012). Model-model pembelajaran mengembangkan profesional guru. Jakarta : Raja Grafindo Persada.

Taufiq. M.A (2009). Inovasi pendidikan melalui problem based learning. Bagaimana pendidik memberdayakan pembelajar di era pengetahuan. Jakarta: Kencana Prenada Media GroupArends, 